http://www.jfas.info

\title{
OPTIMIZATION OF VAPEX OVER CONSUMPTION IN ONE OF THE HEAVY OIL CLEFT STORE
}

\author{
I. Nabi pour ${ }^{1, *}$, M. Hussein Qhazanfari², Q. Zargar ${ }^{3}$ \\ ${ }^{1}$ Oil industry faculty, science \& research branch, Islamic Azad University, Tehran, Iran \\ ${ }^{2}$ Sharif industrial university, oil and chemical engineering faculty, Tehran \\ ${ }^{3}$ Oil engineering faculty, science \& research branch, Islamic Azad University, Tehran, Iran
}

Published online: 20 July 2016

\begin{abstract}
The process of solvent vapor extraction is a recycling method for the heavy oil application that the light hydrocarbon vapor is used as a solvent to reduce the heavy oil viscosity. The primary low recycling and the lower production flow compared with the thermal methods have faced the field applications with limitation due to the slow identity of the solvent penetration procedure in the heavy oil,. So in order to optimize and increase the production in this process, a simulation study was performed on one of the heavy oil cleft store of Iran and the solutions were presented to increase the oil recycling in this process. At first after construction of a cleft two dimensional store with multiple blocks that show the solvent vapor flowing in the cleft net, the optimization process was analyzed around two axes. First the optimization strategies presented to optimize the constructed solvent system injection in the process. Then the formation and distance between producing wells and injection on the process performance and the best condition were evaluated and developed.
\end{abstract}

Author Correspondence, e-mail: imannabipour195@yahoo.com doi: http://dx.doi.org/10.4314/jfas.v8i2s.155 
The results showed that the solvent composition injection method through the producing well in addition to produce the injecting well in first ten days of process with more pressure and the well formation model with subsidiary distance and the vertical determined distance, the most optimized producing performance was presented compared to other plans, this results increase the security about the field application in the VAPEX process at cleft stores

Key terms: optimization, solvent vapor extraction, heavy oil, cleft stores, wells formation

\section{INTRODUCTION}

In the VAPEX process the hydrocarbon process is used for the tar or heavy oil excavation through the horizontal wells. Of this procedure limitation we can point out to the primary recycling and production in lower level compared to the thermal methods as steam assisted gravity drainage SAGD due to the slow identity of solvent penetration in the heavy oil that leads to the oil protuberance, reduction of viscosity and asphaltene removal, regardless of many studies on different aspects of VAPEX, few studies are accessible to increase the oil production and make them efficient and it is necessary to perform more researches in this field.

This process was invented in 1989 by butler 2 and mokrys3. Also some of the laboratory studies and simulations which are performed on this process in the cleft models and without cleavage and different factors as the progressing in the solvent, the injection type and penetration coefficient are evaluated that are Doss in 2005, Azin et al in 2005 and 2008, Haqhiqhat and Mainy in 2008, Rahnama et al in 2008, Fatemi and Bahonar in 2009, Azin and Hasan pour in 2011, pour Abdollah et al n 2012, Alhad Harami in 2014. Azin et al in 2005 proved that such process could be applied for the cleft stores and they realized that the cleft presence could be a benefit for the solvent expansion around the matrix blocks and it might lead to more contact between the solvent and heavy oil.

In this activity by simulation of the VAPEX process in a cleft store model, we process to present and develop the strategies to optimize the production process through evaluation of the formation effect and distance between the producing wells and injection and finding the optimize formation and the presentation of strategies to optimize the production and increase of recycling in VAPEX process and the obtained results were evaluated and assessed with the simulation studies results and Azin laboratories tests and then the results were compared with the butler and Jiang tests 


\section{2-the research methodology}

\section{2-1- the VAPEX process simulation model construction}

The constructed rectangular model in this activity is similar to the tow dimensional models and Azin et al laboratory tests that such process was simulated in two dimensional models of cleft and none-cleft in single block and multiple blocks. The mentioned model was analyzed in the form of a two dimensional and cleft of multiple blocks that represents a cleft carbonated store from the double covetous type and by the use of builder module of CMG numerical simulation software version 2007 and the process optimization with the stars modules from this software and then it was presented in the figure 1 that is the vertical section of a horizontal well in store. The oil specifications applied in the modeling derived from the Kohmand heavy oil field that the stone or the fluid information was available, the model specifications is presented in table1.

An injector is located at the top of the model and a producer is installed exactly at the bottom model in the cleft layers, the oil saturation pressure is 624 pam, so there is no free gas in the model according to the operational condition in all procedure phases as fixed because the operational condition is simulated at the top of the bubble point in all times, so the model could be considered at the sub-saturated store. The similar store matrix specifications and the homogenous model are also regarded. The selected solvent composition applied in this study is the optimized solvent in the produced oil that after an analysis on the hydrocarbons types and gases carrying condensation and its effect on the recycling coefficient increasing and producing the accumulative oil was obtained and the criterion for selection was the closeness to the sea in the saturation condition, in this case the dew point. This criterion should be paid attention to avoid any liquidation in the solvent before being solved in the heavy oil, James in 2009 , Freindrich in 2005, also it should be mentioned that there should not be any watering in the store and the water production should be were low in the store and it should be ignored. The injection flow should be adjusted about 20 square foot in day that continuously it was injected for 60 days and the injection pressure was considered 1500 pam, little more than the dew pressure of solvent composition and the injection solvent was $140 \mathrm{~F}$ in the store temperature and the pressure limitation of the producing well at the bottom was attributed at 900 pam. Also the model size was partly small that the simulation model was small that the simulation time was not a limiting factor in this activity. Figure 2 shows the oil viscosity after the operational time in the described network model. It is clear that the progress and development of solvent flow follows the similar model in the laboratory studies and the previous researchers simulation, butler and Mokerys in 1991-1998, doss and butler in 1998 
and Azin et all in 2005, 2008. According to this figure due to penetration and solving the solvent, oil viscosity is reduced during time.

\section{2-2-Cleft network effect}

The constructed model that shows the VAPEX performance in the cleft carbonated stores includes the surround ding matrix by the vertical and horizontal cleavages. The process was operated and it was observed that the Azin et al studies in 2005 at the beginning or VAPEX process steps in the cleft system of oil- solvent contact surface is shaped and it is development in all direction of matrix and the oil coil is mostly formed in the solvent chamber fast and it is relieved to the block center and in the next phases on the process, the solvent zones are composed of all neighbors blocks and it forms a solid solvent that will be similar to the solvent flow in the models without the cleavage. In the carbonates store with low permeation, the net will provide the communication cleavage for solvent flow that the solvent could form the flow faster and prepare the solvent fingers at the primary levels and it could arrive to the further distance in the injection well, Fatemi and Kharrat in 2011.

Table 2: the simulated model specifications;

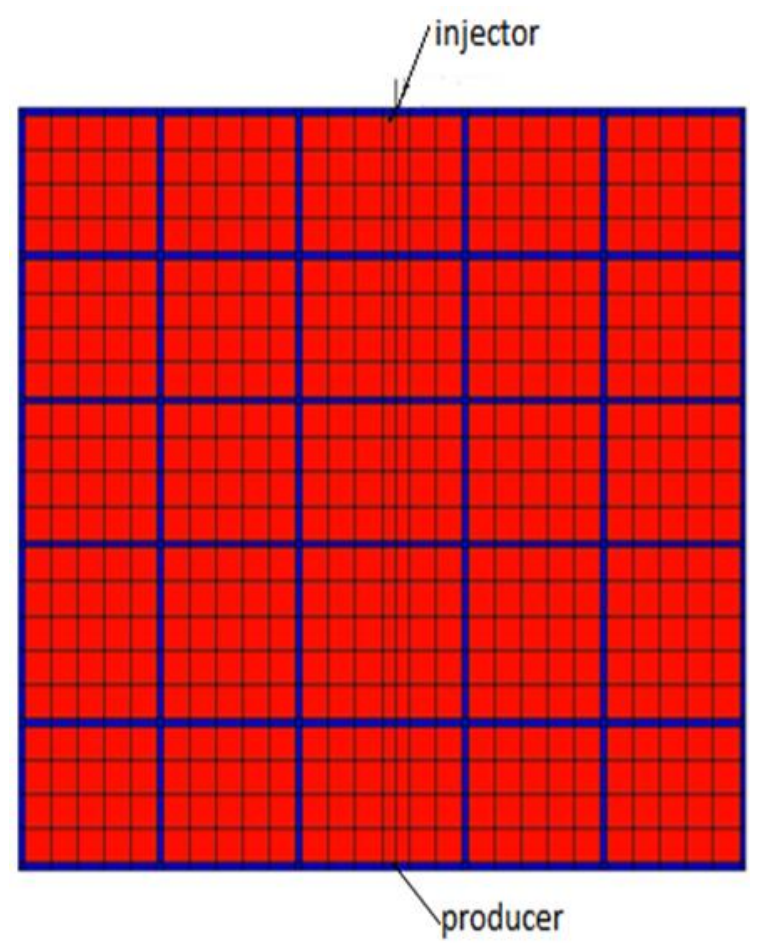

Fig.1. Two dimensional model width section in the cleft network (model 1) 
Table 2. The simulated model specification

\begin{tabular}{|c|c|}
\hline Grid type & Cartesian \\
\hline Grid number in $\mathrm{x}, \mathrm{y}, \mathrm{z}$ direction & $\begin{array}{c}15 \times 1 \times 32 \\
\text { (total grids= } \\
480)\end{array}$ \\
\hline Thickness of each matrix grid (ft) & 0.5 \\
\hline Fracture layer thickness (ft) & 0.1 \\
\hline Matrix porosity & 0.0631 \\
\hline Fracture porosity & 0.008 \\
\hline Matrix permeability (md) & 100 \\
\hline Fracture permeability (md) & 5000 \\
\hline $\begin{array}{c}\text { Pseudo components number of } \\
\text { equation of state }\end{array}$ & 11 \\
\hline Temperature $\left({ }^{\circ} \mathrm{F}\right)$ & 140 \\
\hline Initial pressure (psi) & 927 \\
\hline Bubble point pressure (psi) & 624 \\
\hline Initial water saturation & 0.4 \\
\hline residual oil saturation & 0.1 \\
\hline Number of injection wells & 1 \\
\hline Number of production well & 1 \\
\hline Injection solvent system (mol \%) & $\begin{array}{l}0.3 \mathrm{C} 1+0.25 \\
\mathrm{C} 2+0.45 \mathrm{C} 3\end{array}$ \\
\hline
\end{tabular}

Another important point in the molecules was penetration coefficient effect of injecting solvent in oil. In this study the penetration coefficient was applied for all solvent composition and it is derived from the comprehensive studies to determine the optimized solvent composition for VAPEX process in a heavy oil store, Hosseinipour and Azin in 201 and Shikha et al method obtained in this study was assumed in all performed procedures. 


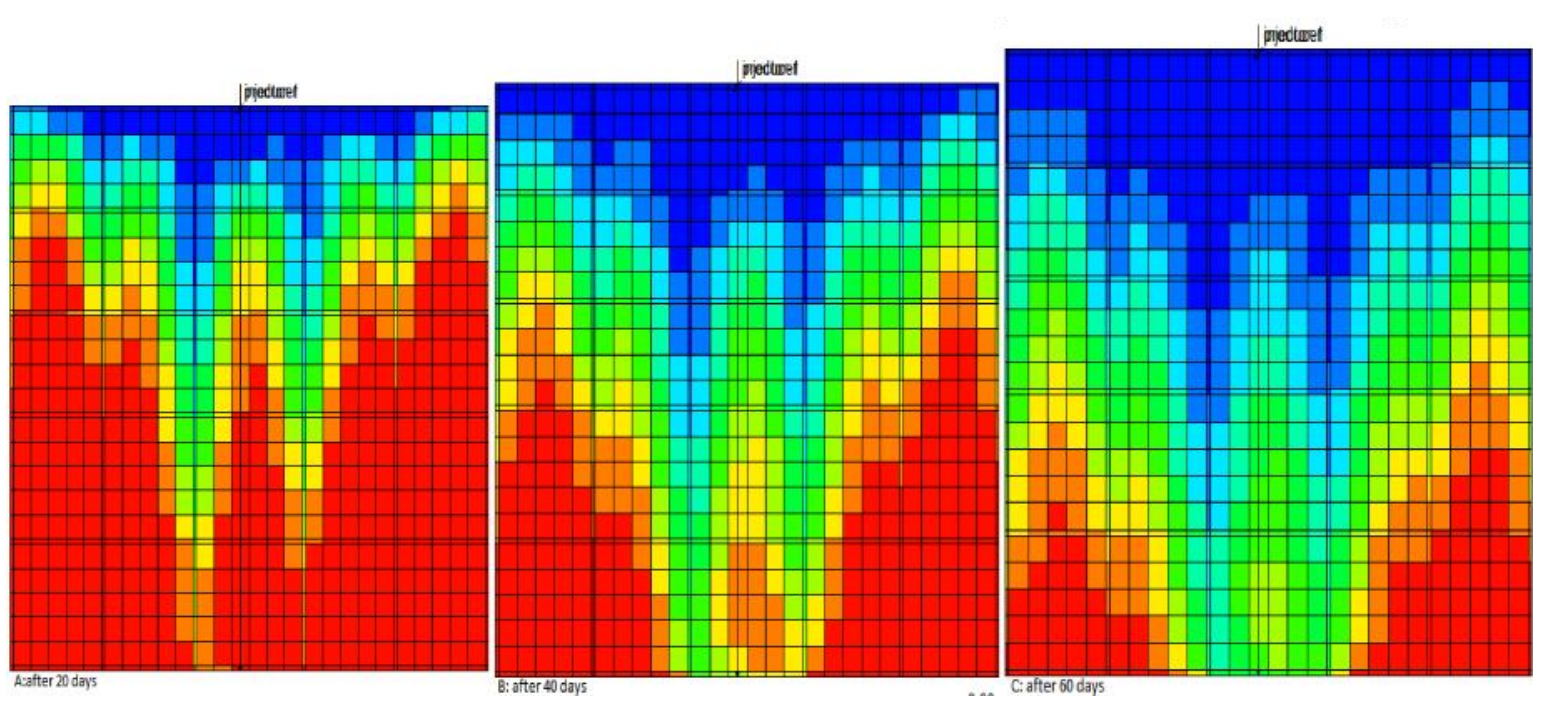

Fig.2. The oil viscosity profile in the process different procedure at the double dimensional cleft network based model

\section{3-results and discussion}

\section{3-1-the solvent composition injection optimization}

Determination of the rate and how the solvent is injected are not the mere concern rather it is economical issue. The discussion in this section is limited to the programed injecting effect on solvent on the production performance based on the simulated results and the economical aspect in this effect will not be evaluated. The simulation results in this activity is accordant to the previous researchers studies, Jiang in 1997, Azin et al in 2008, Hosseinpor and Azin in 2011, the increase of solvent injection flow is affected with definite amount and with formation and definite wells distance due to injection of more solvent to the model and more oil is influenced, the production of cumulative oil is increase although the produced oil is improved in quality due to penetration and solvent solving and its viscosity is reduced.

In this part other formations are evaluated about the solvent injection flow and its influence on the VAPEX producing performance, by this difference that the rectangular model of the cleft network, it is simulated and developed or in another word some of the laboratory activities performed by butler and Jiang in 1997 that mostly were developed on the none-cleft models, in this model some of the cleft two dimensional models were elaborated more. In this part except the injection floe condition other model parameters are fixed and actually other ideas were used to optimize the VAPEX process optimization, these methods are as below:

- The injection through the producing well in addition to the injection well for first 10 days of simulation with more pressure 
- The primary more injection flow

- The more primary injection flow with the methane injection only

\section{3-1-1- injection through the producing well in addition to the injection well for first 10 days of simulation with more pressure}

Design in this method performed on a way that in addition to the solvent injection to the horizontal well at the top of the horizontal producing well, the producing well also is injected in 10 days of simulation and the solvent injected to the model but with 2000 psia pressure and then after 10 days again the lower horizontal well is changed to the producing well, the injecting pressure in the above well is fixed with the same pressure of $1500 \mathrm{psia}$, in first 10 days there is no producing simulation from store and only the solvent composition is injected to the model and also it is the soak time for the solvent for dilution and this pressure assist the solvent vapor expansion around the well specially through the cleavages network. The obtained results from these evaluations is presented in figure 4 and 5 and as it is observed this method has the most recycling and cumulative oil production and it is advised as the optimized method to increase the oil production in the process. About such result we can say that first of all in this condition, the solvent is injected more than the usual condition to the store and after 10 days from injecting, more oil is effected by the solvent even to some diameters around the producing well, so more area of store is accessible for the solvent, second that could be the important reason is the simultaneous injection from two wells at the beginning will stabilize the relation between two wells and the production is facilitated and it will lead to the injectivity at store and it has more primary recycling compared to the usual condition, this method when the store oil has high viscosities could be used beneficially to make relation between the injecting and producing wells, this method schematic is presented in figure 3 , as mentioned before the dew pressure is the criterion to inject solvent composition in the close pressures to the solvent saturation that most of solvability and penetration to the oil and as the result the most recycling is obtained and the injection with more pressure through the injecting well according to other researchers studies results and simulation performed in this activity has not led to the oil recycling increase, rather it could lead to emergence of reaction risk of solvent without the proper effect on the heavy oil and making pressure surges intensively in the store and as the result it will cause the store breaking and more costs to provide the higher pressures and sedimentation and asphaltene fouling, Azin et al in 2008, Jiang in 1997 


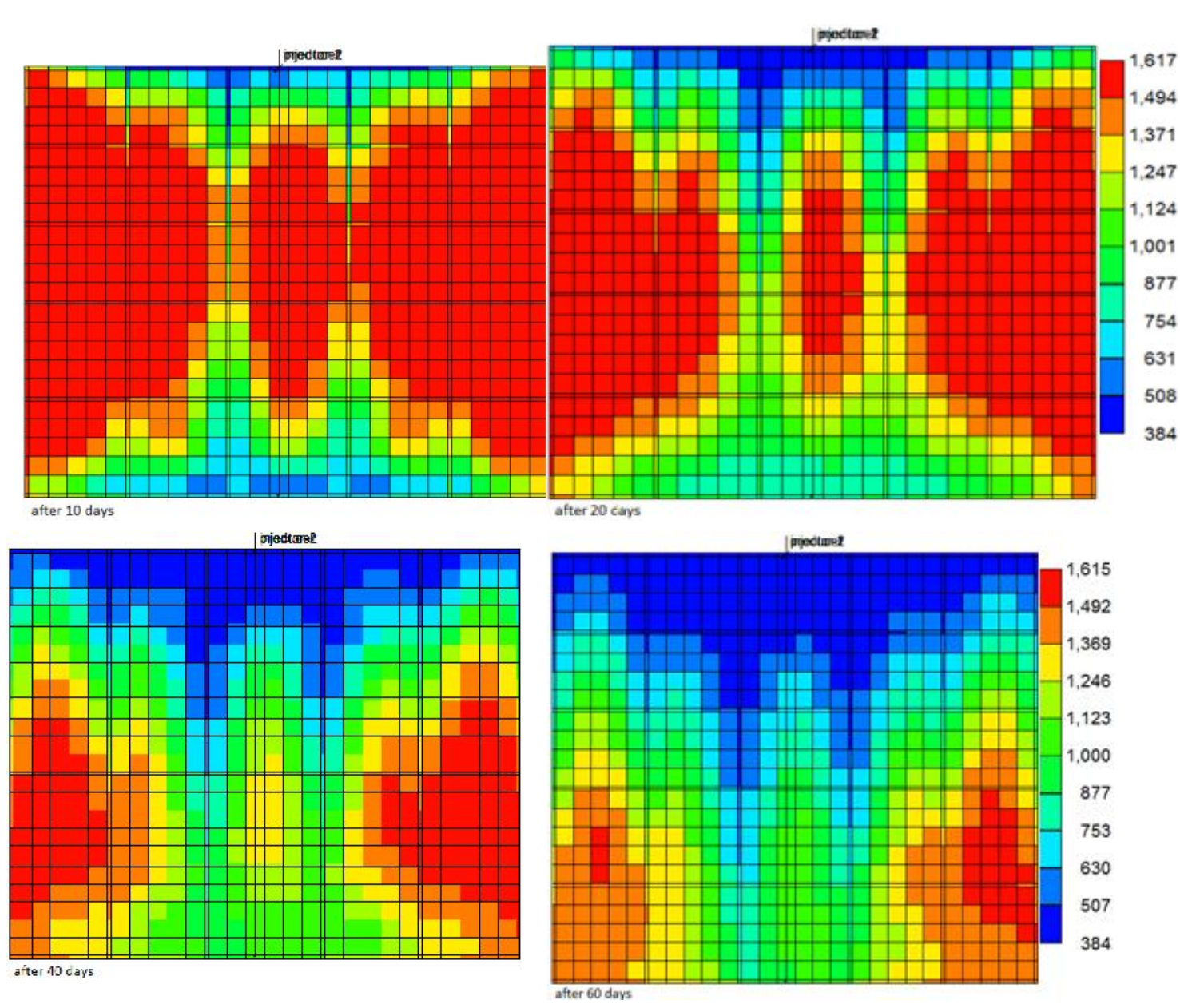

Fig.3. The oil viscosity profile within time passage in the injection model through the producing well in addition to injecting well for first 10 days of simulation

\section{3-1-2- injection with primary flow for first 10 days of simulation}

Two conditions are evaluated in this section, one of them is the solvent composition injection with the higher primary injection of $30 \mathrm{ft} 3 /$ day and other one is the methane injection only at the first days of simulation with the same injection flow. Designing this method is due to the solvent injection with primary higher flow to construct and distributes the solvent concentration in the oil fast. This method is the benefit for the stabilization and movement fixation and primary displacement improvement in the store model cleft store. This method has better result compared to the solvent injection with fixed flow in the total process time and leads to the oil production in addition to the lower accumulative solvent that is still confirmed by the butler and Jiang experiments results in the none-cleft physical models, 1997. Another presented model which is similar to this model that presents the methane injection with more flow during first 10 days of simulation and in the continuity the injection with the constructed solvent system that according to the figure 4, 5 graphs will have more recycling compared to the two dimensional cleft typical model and it is lower than the model 
at the beginning of process with the more solvent injection flow and other benefit is the requirement to the fewer solvent consumption.

It should be noted that the strategies and runs were used in this direction to optimize the production in process and again it was analyzed about sensitivity and the most favorable was presented for the recycling criterion in this activity, even the model was made by combining two mentioned plans that could not provide more recycling from the primary optimization method, the obtained results from this model simulation and comparing with the presented types are shown in figure 4 and 5.

According to these graphs it is observed that the injecting model through the producing well in addition to the injecting well with higher pressure at the beginning of process compared to other models had more recycling coefficient, 27.7\%, although at the first 10 days, there was no production in the process, after that the injection model of solvent and primary flow at the 10 days of processes beginning, 27.2\% of recycling coefficient and the methane primary injection at the beginning of the process first 10 days the recycling coefficient was $26.1 \%$ and the cleft network basic model with the solvent flow fixed injection, it had the lower recycling coefficient at $25.4 \%$ compared to other conditions.

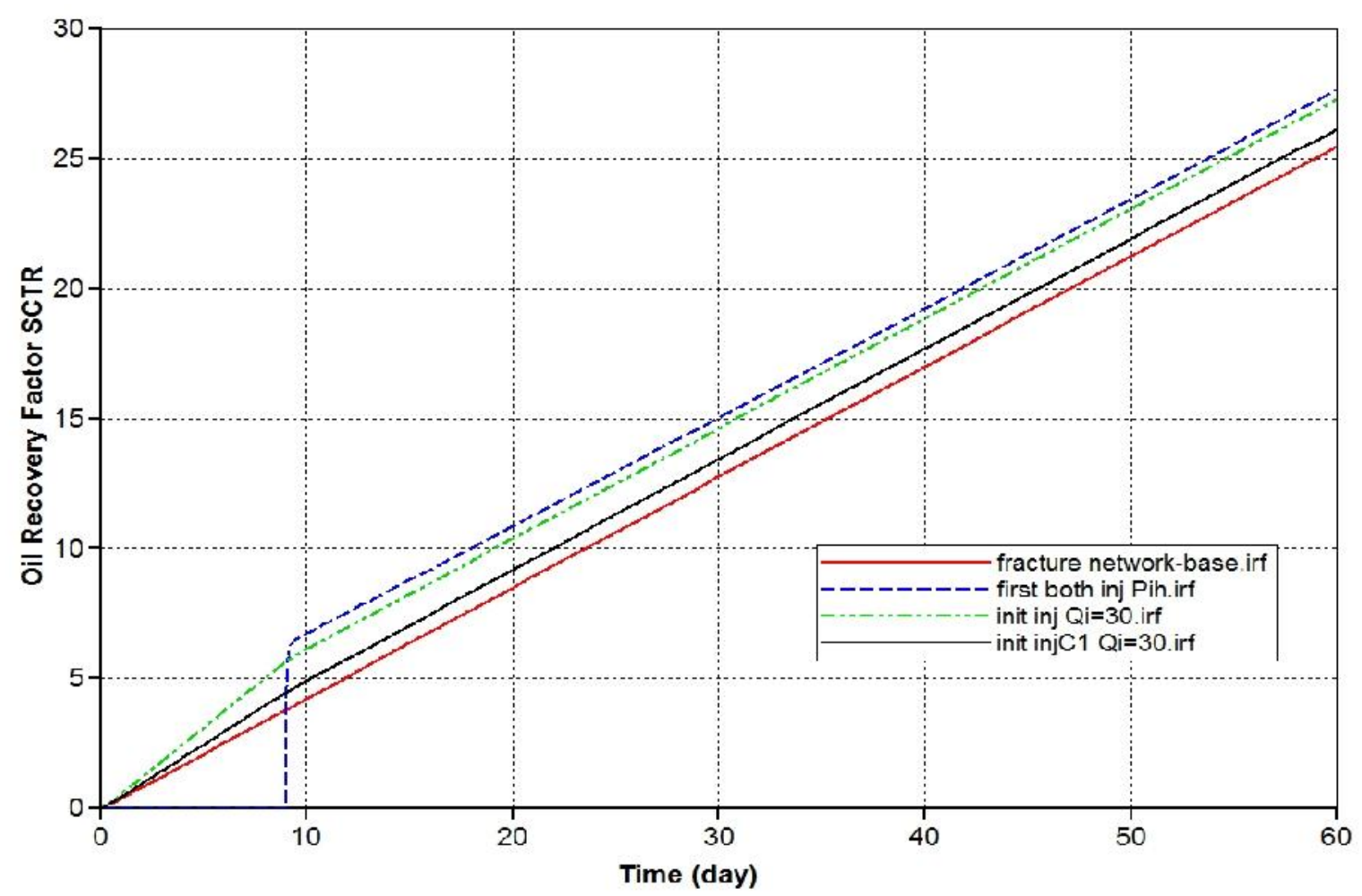

Fig.4. The oil recycling coefficient with time at the production process optimization plans 


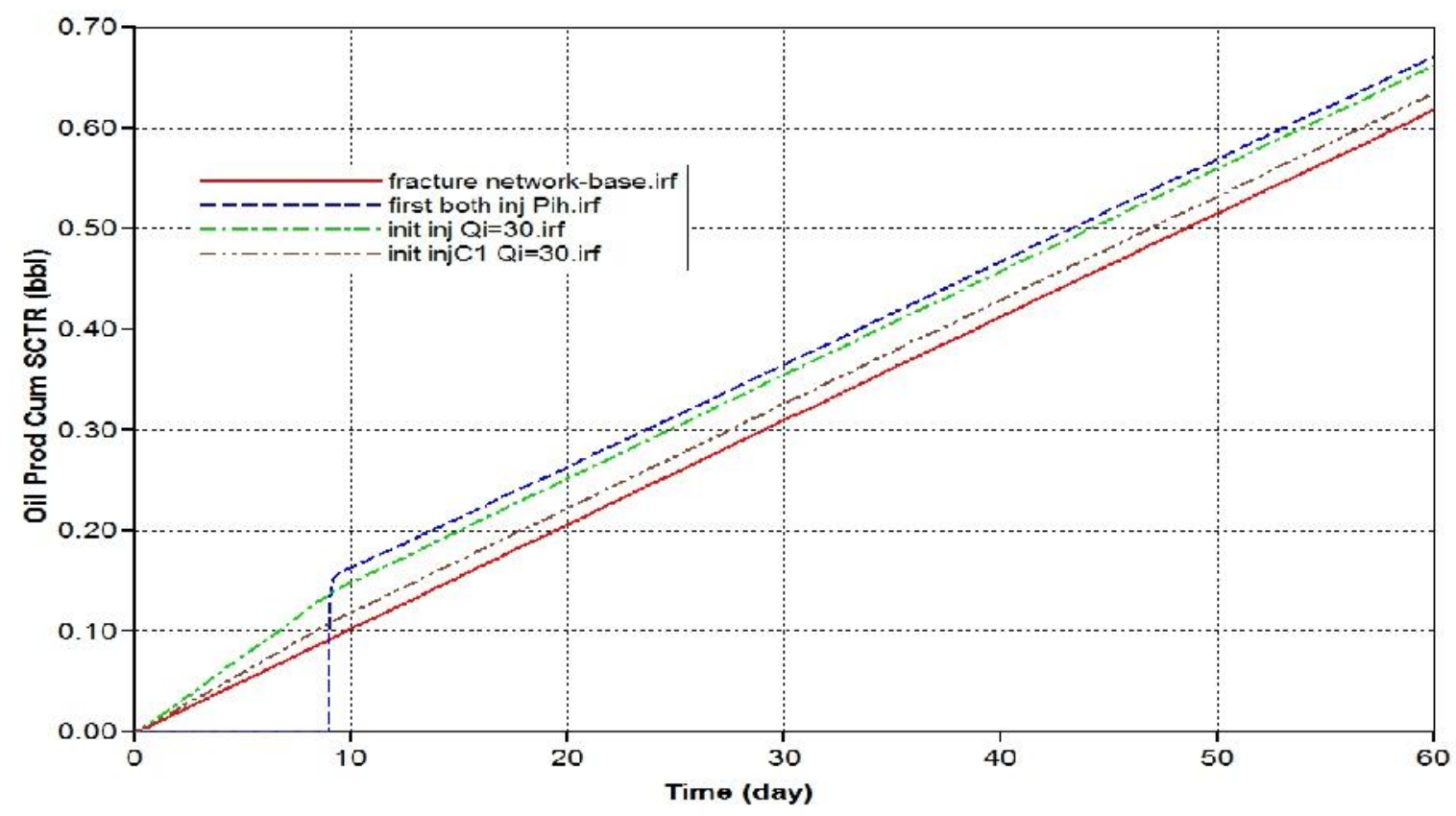

Fig.5. The oil cumulative producing graph with time at the producing process optimization plans

\section{3-2-VAPEX process optimization with the formations and different distances in the injecting and producing wells}

The location and distance between the injection wells is an important and sensitive issue in the VAPEX process, when the gravity force is dominant, the horizontal producing well is located close to the store bet with distance to the oil-water contact level. But the injecting well location could be variable. The proper selection of well positioning is important in the primary displacement control. The more important issue is the wells figure location controls the gas chambers profiles, also the asphaltene and its effect on the diluted oil flow could be related to the well formation variation that controls the contact surface, Haghighat and Maini in 2008. In heavy oil stores where their oil is moving partially, the injecting well could be located at the store peak while in a tar store with low movement, the horizontal wells could be closed to each other adequately to make their relation as fast as possible, butler and Mokrys in 1993. The viscosity of crude oil is the main parameter to determine the distance between the VAPEX wells, the formation variation and distance between wells in VAPEX that were evaluated in the laboratory studies by butler and Jiang in 19978 and Azin simulation studies et al in 2008 on the two dimensional models without the cleft and nonecleft stores. In this project the two dimensional model introduced cleft network were evaluated and developed, so 5 formation of the injecting and producing wells were designed 
on the basis of cleavage network. Different formations evaluation in this project and the heavy oil viscosity profile is presented during the process in figures 6 to 10 and the obtained results were presented in graphs 11 to13.

Model 1 is the same basic model for the described cleavage network in previous part, figure 1 and the viscosity reduction profile was presented in figure 2 during the process and in model 2 the injecting well is located exactly on the producing well but with the lower distance compared to the model 1 , figure6. In the model 3 according to the figure 7 , the injecting well is located at the left corner and the producing well is at the right side in the bottom and with the most distance from each other, in model 4 the producing well is located at the right side in the bottom and the injecting well is in the left side above the model and lower than the injecting well of model 3 and distance between two well is fewer, figure8. In model 5 according to figure 9 the injection is done from the bed of model as the injection well is located at the bottom in right side of model in the cleavage layer, in addition to this issue, a model with two injecting wells are located at the top of model and producing well in the down cleavage between the model as model 6 , figure 10 to observe the effect on two injecting wells on the production procedure and it was compared with other models.
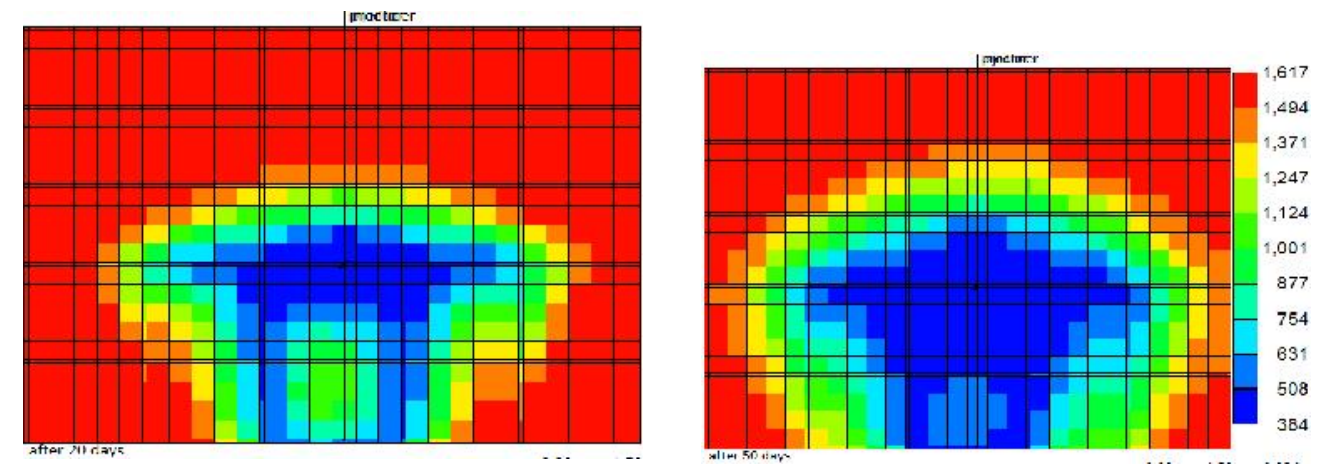

Fig.6. The oil viscosity profile in the model no.2 during operation

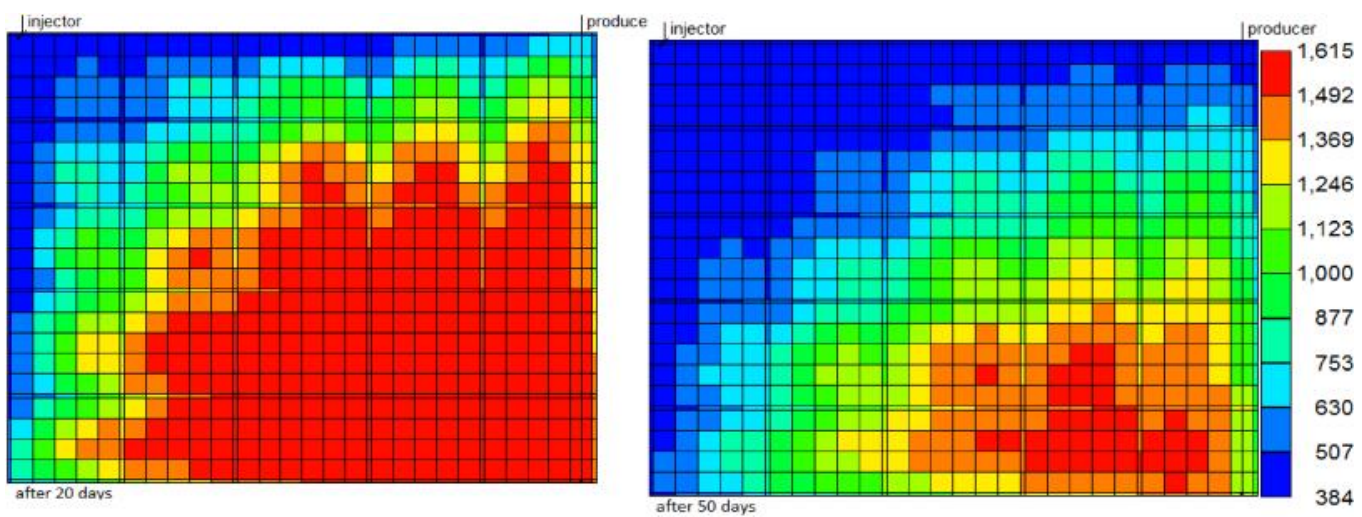

Fig.7. Oil viscosity profile in model 3 during operation 


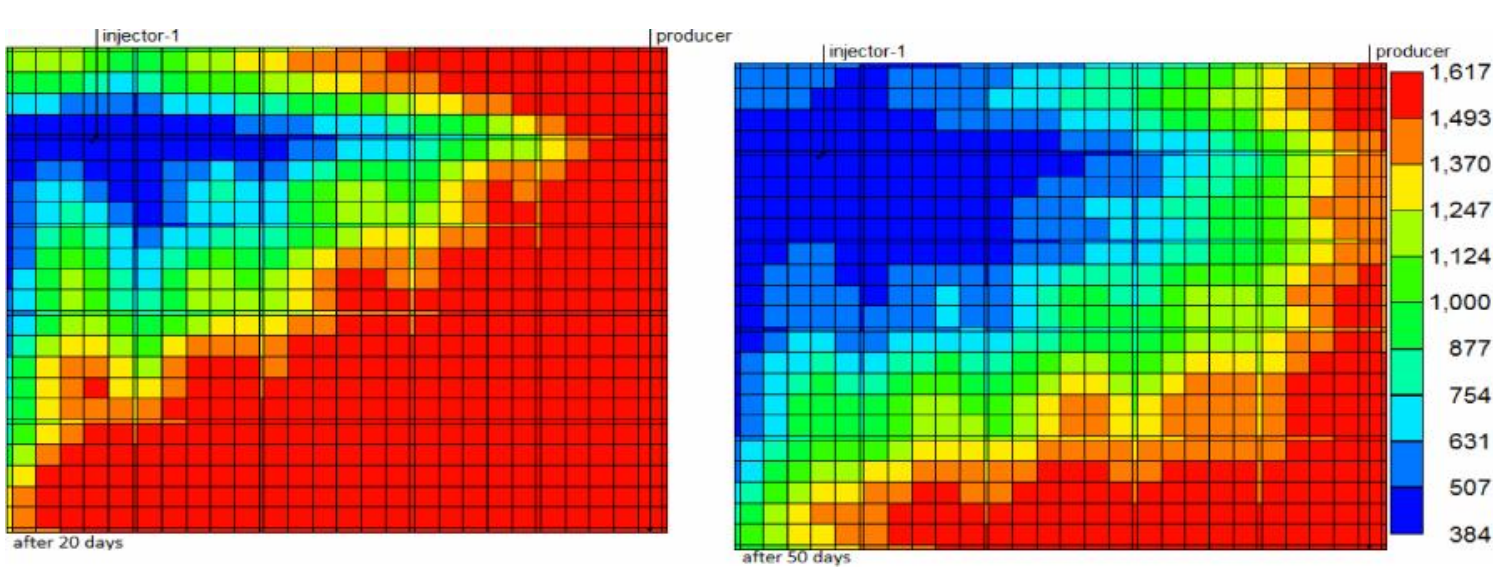

Fig.8. Oil viscosity profile in model 4 during operation

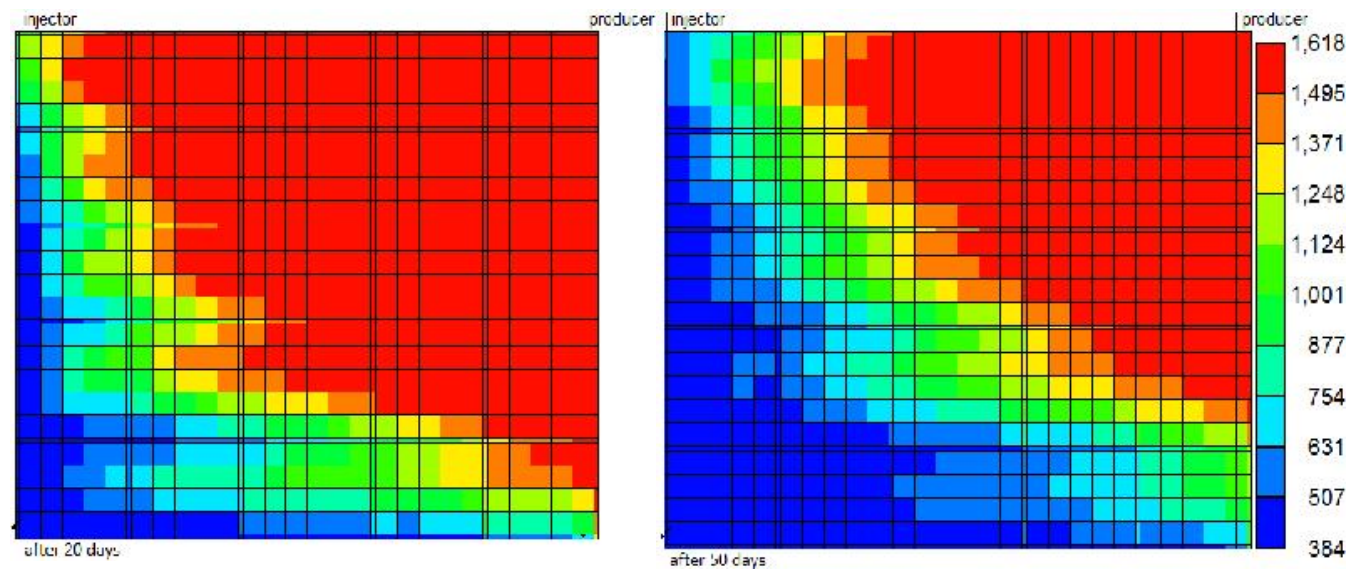

Fig.9. The oil viscosity profile in model 5 during operation

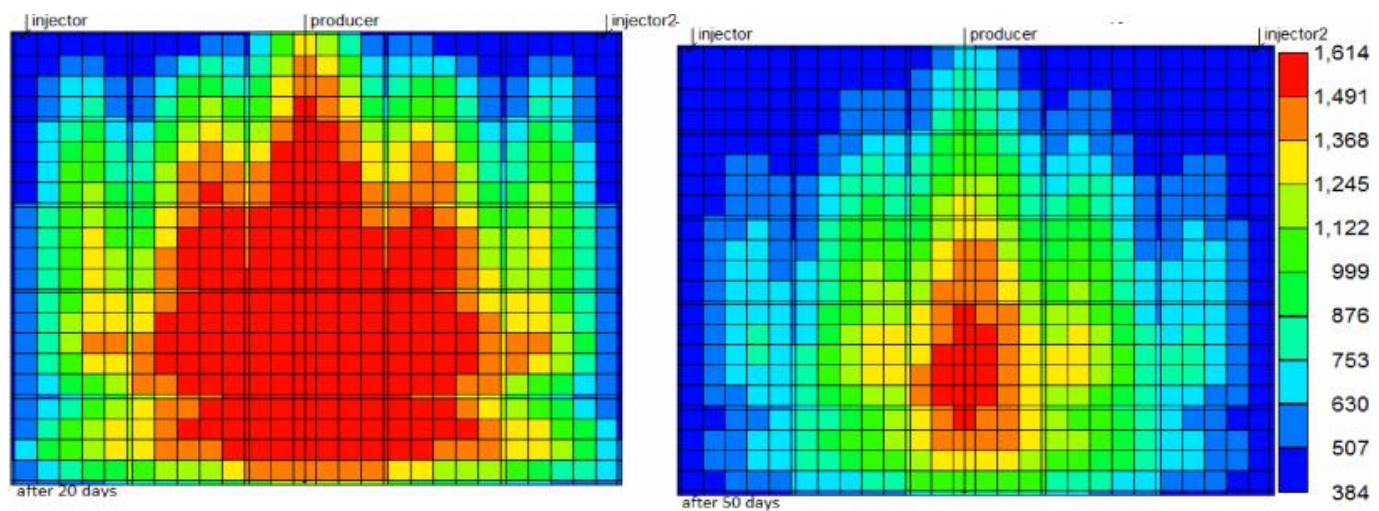

Fig.10. Oil viscosity profile in model 6 during operation 


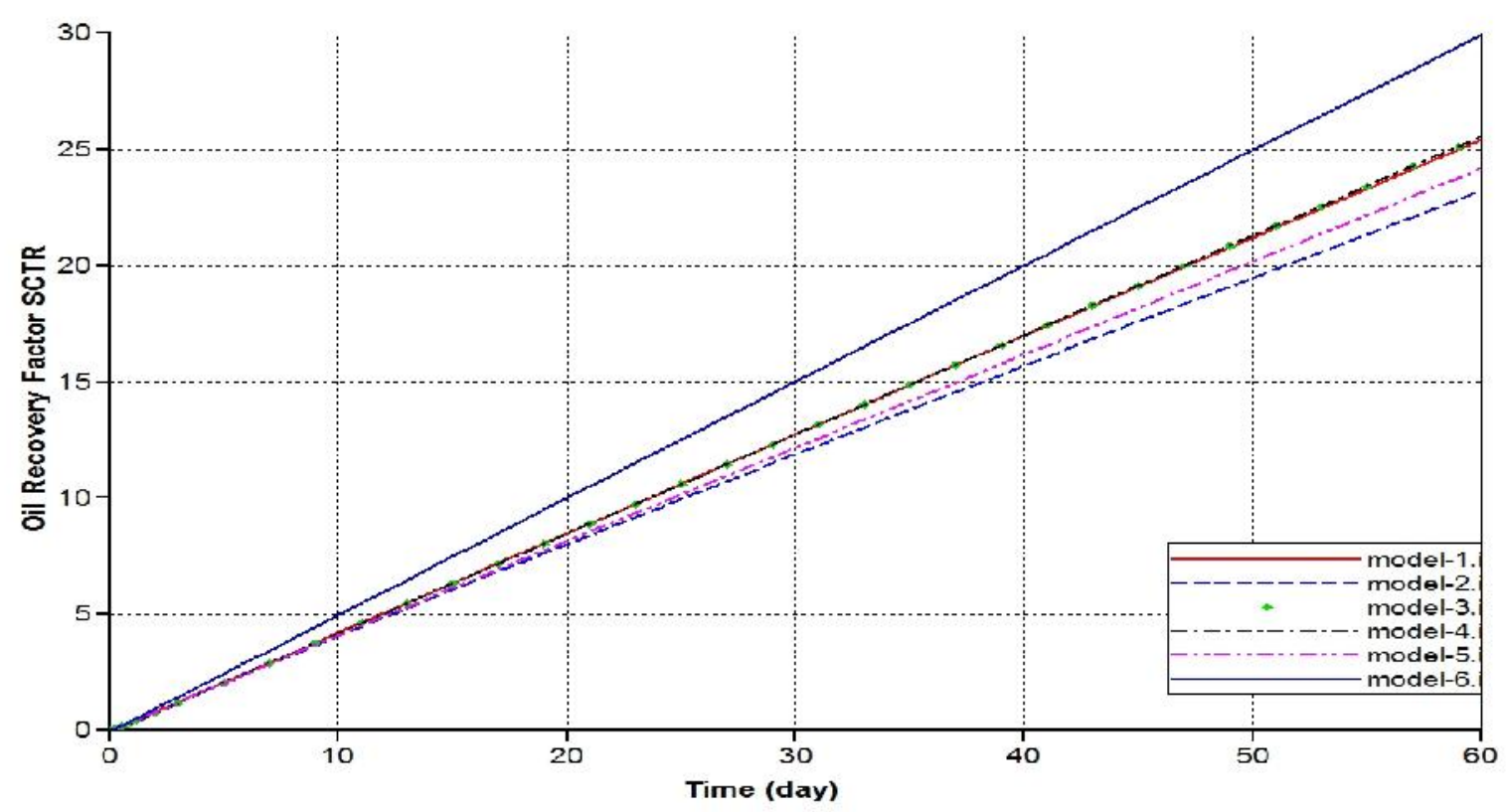

Fig.11. The recycling coefficient of oil with time during different formation of wells in the cleavage network

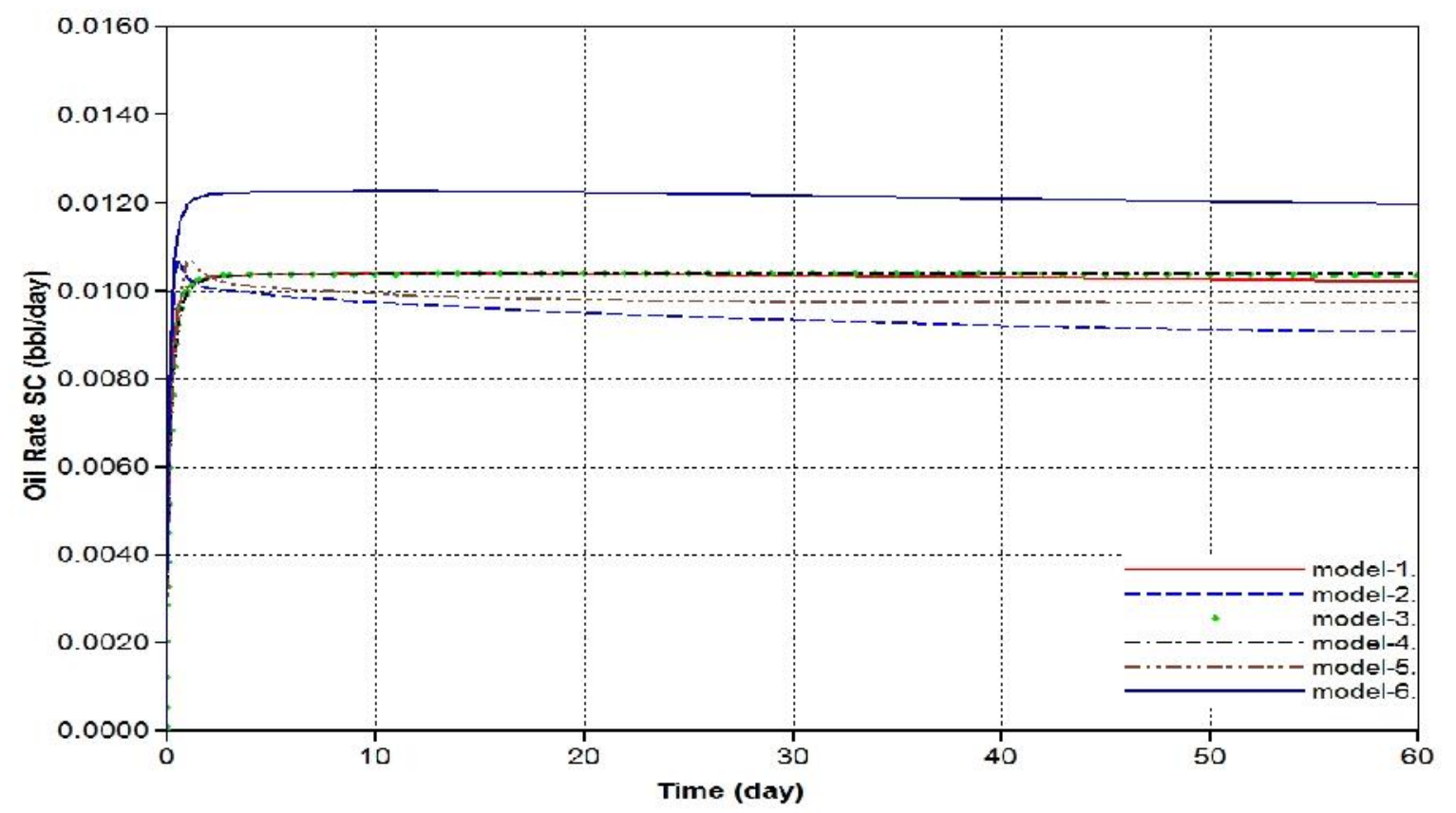

Fig.12. Oil production ration with time in wells different formation 


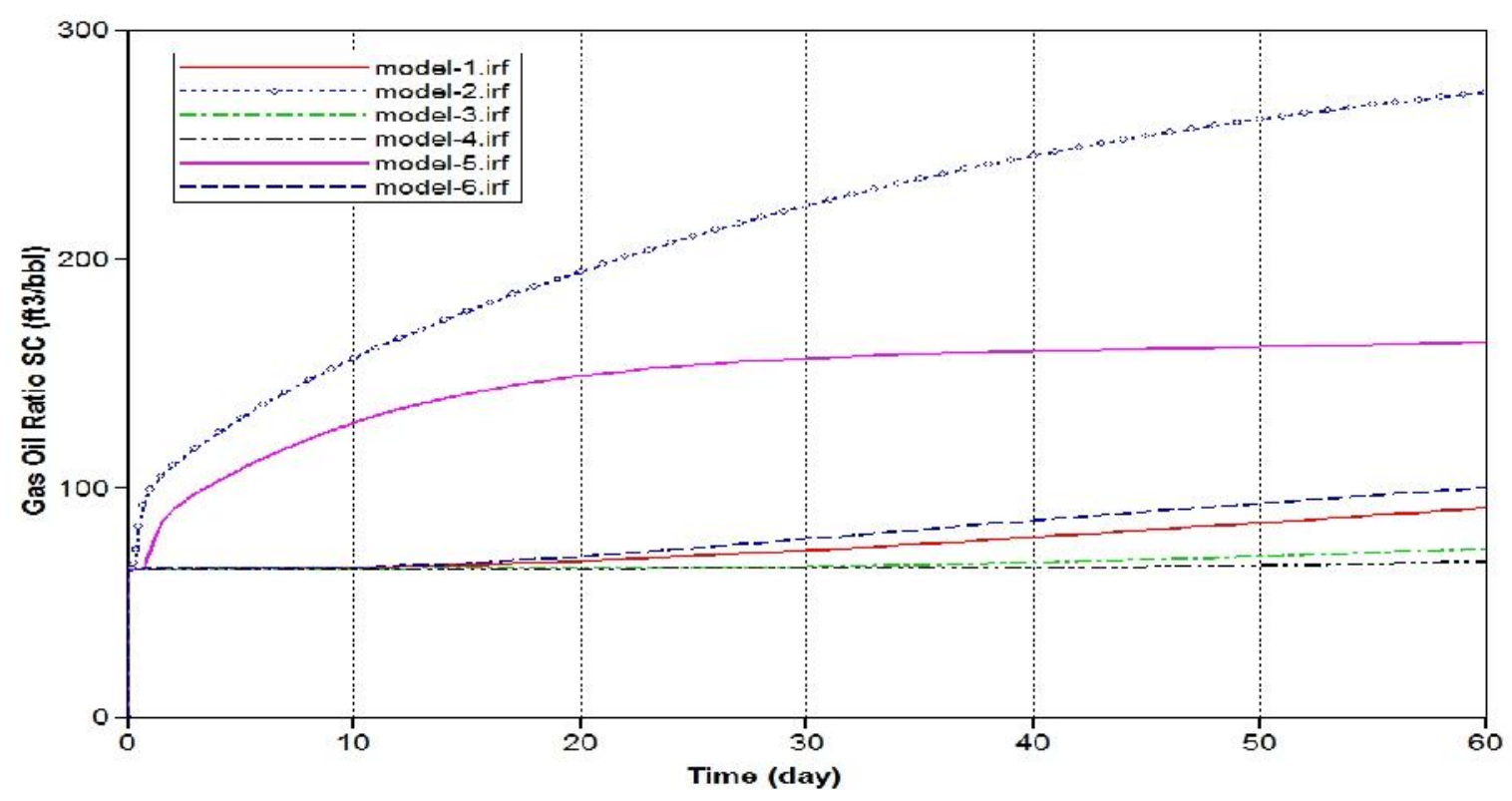

Fig.13. Oil to gas comparison with time in wells different formations in cleavage network

As it is observed in figure 11 and 12, the model 6 had two injecting wells and the most recycling with $29.93 \%$, as according to figure 13 the oil- gas ratio is more than the optimized models with one injecting well like 3 and 4 and of course lower than models 2 and 5. Because the model with two injecting well has bigger solvent chamber compared to other models and according to figure 10 in the model, it has more expansion and more heavy oil is diluted, also model 4 with the subsidiary distance between the injecting and producing wells has obtained the most recycling coefficient at $25.8 \%$ between models with one injecting wells.

Although due to the model small size, results do not present high differences between optimized conditions of 1, 3, 4. In VAPEX process the producing and injecting wells distance from each other is usually regarded close together, then this process is applied $n$ the heavy oil stores, where the oil movement has high viscosity and it is necessary to solve the solvent to prepare the producing process. If the wells are located in the far distance from each other as model 3, the heavy oil requires a displacement mechanism for production that such mechanism is not possible in the heavy oil stores easily, on the other hand if wells are located close together similar to what occurred in model 2, the danger of fast cracking without effective contact with oil is increased and this issue has more important in cleft stores because the danger of short cut between injecting wells and producing through the cleavage network is more, the results showed that as more the distances between wells are vertically and in subsidiary, model 4, due to late reaction of solvent vapor in the cleavage network and also the more assessable area in the store, more oil is produced, the fast reaction obviously 
leads to low effect of VAPEX process and lower contact of solvent with heavy oil, model 2 and 5, therefore the wells locations is the critical issue in application of VAPEX in cleft stores. One of the benefits is the wide subsidiary distances between producing and injecting wells that when then relation between wells is made due to wider contact surface of oil, gas and emersion, more oil is produced. Anyhow the more distance between the injecting and producing wells, will postpone the relation between wells. In other word the lower vertical distance between wells could reduce the oil production start time, but the produced oil directly is dependent to the oil volume transference and injecting solvent, when the injected solvent was saturated, the transferring area of vaporizer could be expanded all around the gas area from the emersion processes. By increasing the vertical distance of two wells, the solvent is expanded slowly in the gas area and more part of solvent is observed by oil butler and Mokrys in 1993, as more the distance between wells increase solvent vapor contact area with oil also will increase. So combining also increased, Jiang in 1997. According to figures 9 and 12 in model 5 the oil flow in primary level is a little more than the injection from the model bottom compared to other models with one injecting well that behaves according to the below factors:

1-the higher pressure gradient for the primary displacement in the cleavage network due to lower distance between the injector and producer

2-the width sectional area effective on displacement

3-the increased volume transference between the oil and solvent due to diverse flow made by the increase of gas compositions, Jiang in 1997, Azin et al in 2005, 2008 in the module cleft network

But injecting benefit for long run is made of continuous gas chamber between the injecting and producing that is not protected. Although the crude oil in the vapor region at the top of the injector could be diluted due to solved solvent, it could not effectively discharged to the producing well, because the required moving power for the diluted oil movement was not accessible at the top of the vapor chamber, Jiang in 1997. Also in model 5 due to presence of horizontal cleavage in model between two wells and emergence of faster vapor solvent through them and some part of heavy oil remains unelaborated on the top of the model and the process improper performance is not out of expectation

The results showed that although models with one injecting well have approximately middle production rate, the fixed oil production by gravity and injection from top obviously was more than the injection from the bottom except model 2 that the little distance between two wells and fast cracking of solvent in this cleft model had the most improper producing 
performance and the most gas- oil ratio. Therefore the main differences were within the oil production flows for the injecting locations in the primary displacement and the time of solvent vapor cracking through the cleavage network. As the result in this comparison, the formation and distance of proper wells in model 5 presented the most optimized production and lowest produced gas to oil ratio.

\section{CONCLUSION}

After the numerical modeling of the VAPEX process, by construction of a basic store model in two dimensional multiple blocks cleft store and its validation with laboratory stets and previous researches simulations and observing the special progress type in solvent vapor flow in the store cleft network, the strategies for the process optimization was simulated and the below results obtained:

- Among three presented strategies to increase the VAPEX production outcome, the injecting method through the producing well in addition to the injection well at the first 10 days of process with more pressure, the maximum oil recycling obtained at 27.67 that due to enhancement of injection capability in the store and keeping the wells relation faster and also the oil effecting from the model even around the producing well and giving a remain time to solvent for more diluting. After the injection condition, the solvent combination with primary flow and injecting the methane with more flow orderly will have more effective performance compared to the usual condition due to agility in construction and distribution of solvent concentration in oil and improvement and fixation of primary displacement in the store model cleft network. Also saving the solvent consumption in the time of primary injecting, only the methane was the method benefit.

- In the injection and producing wells different distances and formation, model 6 with two injecting well had the most recycling coefficient with $29.93 \%$ due to having the larger solvent chamber and covering more are of store area.

- Among the models with one injecting well, model 4 with vertical and subsidiary distance between wells has the most optimized producing performance compared to other models with recycle coefficient of $25.8 \%$ and it is also understood that the fast cracking through cleavage network obviously leads to low effect of VAPEX process and lower contact of solvent to heavy oil as models 2 and 5. The wells location is the critical issue in application of VAPEX in the cleft stores as by increase of distance between wells in vertical and subsidiary condition with definite rate ( similar to model 4) more oil is 
produced due to late cracking of solvent vapor in the cleavage network and the solvent vapor more contact area length with heavy oil.

\section{REFERENCES}

- Friendrich, K."Effect of a non-condensable gas on the VAPEX Process" a thesis presented to the University Of Waterloo, Ontario, Canada in fulfillment of the thesis requirement for the degree of M.Sc. in Chemical Engineering, 2005.

- Jiang, Q. "Recovery of heavy oil and bitumen using VAPEX Process in homogeneous and heterogeneous reservoirs", Ph.D. Dissertation, the University of Calgary, 1997.

- Butler, R. M, Mokrys, I. J," Recovery of Heavy oils using vaporized hydrocarbon solvent: Further development of the VAPEX process" JCPT.The journal of Canadian Petroleum technology, 1993.

- Azin.R, Kharrat.R, Ghotbi.C, Rostami.B, Vossoughi.S, "Simulation study of the VAPEX process in fractured heavy oil system at reservoir conditions" Journal of petroleum Science and Engineering, 2008 : 51-66.

- James.L.A, "Mass Transfer Mechanisms during the Solvent Recovery of Heavy Oil" a thesis presented to the University of Waterloo, Ontario, Canada in fulfillment of the thesis requirement for the degree of $\mathrm{PhD}$ in Chemical Engineering, 2009.

- Hosseinipour.A, Azin.R. "Comprehensive Study to Determine Optimum Solvent Composition for VAPEX In a Heavy Oil Reservoir” SPE, 2011 : 144-270.

- Haghighat.P, Maini.B.B, "Role of Asphaltene Precipitation in VAPEX process" Schulich School of Engineering, University of Calgary, PETROLEUM SOCIETY, and PAPER 2008-087-presented at the Canadian International Petroleum Conference/SPE Gas Technology Symposium 2008 Joint Conference Calgary, Alberta, Canada, 17-19 June 2008

- Fatemi.S.M, Kharrat. R, "Assessment of VAPEX process performance in naturally fractured reservoirs" Journal of petroleum Science and Engineering, 2011, 75 : 260-273

- Kapadia.R.A, Upreti.S.R, Lohi.A, Chatzis.I. "Determination of gas dispersion in vapor extraction of heavy oil and bitumen" Journal of Petroleum Science and Engineering, 2006, $51: 214-222$.

- Pourabdollah K et al. The VAPEX process, from beginning up to date. Fuel, 2012. http://dx.doi.org/10.1016/j.fuel.2012.12.003 j.fuel.2012.12.003 
- Masihi.M, Rasti.F, Kharrat. R,'Semi-Analytical modeling and simulation of VAPEX process of "Kuh-e-Mond" reservoir" Journal of petroleum Science and technology-LPET2009-0236

- Rostami.B, Azin.R, Kharrat.R, "Investigation of the VAPEX Process in High Pressure Fractured Heavy Oil Reservoirs" SPE/PS-CIM/CHOA 97766, 2005.

- Azin.R, Kharrat.R, Ghotbi.C, Vossoughi.S, "Effect of Fracture Spacing on VAPEX Performance in Heavy Oil Fracture Systems" Iran, J. Chem. Chem. Eng., 2008, 27(1).

- Azin.R, Kharrat.R, Ghotbi.C, Vossoughi.S, "Study of the VAPEX process in fractured physical systems using different solvent mixtures" Oil \& Gas Science and Technology Rev. IFP, 2008, 63(2) : 219-227.

- Azin.R, Kharrat.R, Ghotbi.C, Vossoughi.S," Role of Fracture Network on the Performance of the VAPEX Process in Low-Permeability Heavy Oil Systems" The 11th Iranian Chemical Engineering Congress November 28-30, Tehran, Iran, 2006.

- Azin.R, Kharrat.R, Ghotbi.C, Vossoughi.S, "Improved heavy oil recovery by VAPEX process in presence of vertical and horizontal fractures" journal of Japan petroleum institute, 2007, 50(6) : 340-348.

- Butler, R.M., Mokrys, I.J., Das, S.K.” The Solvent Requirements for VAPEX Recovery", SPE 30293, Presented at the International Heavy oil Symposium Held in Calgary, Alberta, Canada, June 19-21, 1995.

- Azin, R., Kharrat, R., Ghotbi, C., Vossoughi, S," Applicability of the VAPEX Process to Iranian Heavy Oil Reservoirs", SPE 92720, Presented at the 14th SPE Middle East Oil and Gas Show and Conf., Bahrain, 12-15 March, 2005.

- Butler, R.M, Das S.K, "Vapor Extraction of Heavy oil and Bitumen " Department of Chemical and Petroleum Engineering The University of Calgary, Canada, T2N 1N4

- David O. Ogbe, Zhu.T, “ Solvent-Based Enhanced Oil Recovery Processes to Develop West Sak Alaska North Slope Heavy Oil Resources" Final Topical Report, National Energy Technology Lab US Department of Energy, Arctic Energy Technology Development Laboratory University of Alaska Fairbanks, 2002, Alaska 99775

- Moghadam.S, Nobakht.M, Gu.Y, "Theoretical and physical modeling of a solvent vapor extraction (VAPEX) process for heavy oil recovery" Journal of Petroleum Science and Engineering, 2009, 65 : 93-104

- M.M. Al-Hadhrami et al. "Experimental and numerical investigations into the effect of heterogeneities on the recovery of heavy oil by VAPOUR EXTRACTION (VAPEX)" Fuel, 2014, $135:$ 413-426 
- Fatemi.S.M, Bahonar.M, "Simulation Analysis of the Effect of Fractures' Geometrical Properties on the Performance of Vapor Extraction Process" SPE Paper 138400, 2010.

- Muhammad, "Optimal Control of Vapor Extraction of Heavy oil" in partial fulfillment of the requirements for the degree of Doctor of Philosophy in the program of Chemical Engineering, Toronto, Ontario, Canada, 2012.

How to cite this article:

nabi pour I, Hussein Qhazanfari M, Zargar Q. Optimization of vapex over consumption in one of the heavy oil cleft store. J. Fundam. Appl. Sci., 2016, 8(2S), 1966-1984. 